\title{
Assessment of Platelet Respiration as Emerging Biomarker of Disease
}

\author{
A. T. PETRUŞ ${ }^{1 *}$, D. L. LIGHEZAN ${ }^{2 *}$, M. D. DĂNILĂ $\breve{3}^{3}$, O. M. DUICU ${ }^{3,4}$, A. STURZA ${ }^{3,4}$, \\ D. M. MUNTEAN ${ }^{3,4}$, I. IONIȚĂ ${ }^{2}$ \\ * These authors contributed equally to this work as first authors.
}

${ }^{1}$ Department of Anatomy, Physiology and Pathophysiology, Faculty of Pharmacy, "Victor Babeș" University of Medicine and Pharmacy, Timișoara, Romania, ${ }^{2}$ Department of Internal Medicine I Hematology, Faculty of Medicine, "Victor Babeș" University of Medicine and Pharmacy, Timișoara, Romania, ${ }^{3}$ Department of Functional Sciences - Pathophysiology, Faculty of Medicine, "Victor Babeș" University of Medicine and Pharmacy, Timișoara, Romania, ${ }^{4}$ Centre for Translational Research and Systems Medicine, "Victor Babeș" University of Medicine and Pharmacy, Timișoara, Romania

Received September 18, 2018

Accepted January 29, 2019

Epub Ahead of Print March 22, 2019

\section{Summary}

Mitochondrial dysfunction is currently acknowledged as a central pathomechanism of most common diseases of the $21^{\text {st }}$ century. Recently, the assessment of the bioenergetic profile of human peripheral blood cells has emerged as a novel research field with potential applications in the development of disease biomarkers. In particular, platelets have been successfully used for the ex vivo analysis of mitochondrial respiratory function in several acute and chronic pathologies. An increasing number of studies support the idea that evaluation of the bioenergetic function in circulating platelets may represent the peripheral signature of mitochondrial dysfunction in metabolically active tissues (brain, heart, liver, skeletal muscle). Accordingly, impairment of mitochondrial respiration in peripheral platelets might have potential clinical applicability as a diagnostic and prognostic tool as well as a biomarker in treatment monitoring. The aim of this minireview is to summarize current information in the field of platelet mitochondrial dysfunction in both acute and chronic diseases.

\section{Key words}

Blood platelets - Mitochondrial respiration - High-resolution respirometry - Extracellular flux analysis - Acute and chronic diseases

\section{Corresponding author}

D. M. Muntean, Department of Functional Sciences Pathophysiology, "Victor Babeș" University of Medicine and Pharmacy of Timișoara, 2, Eftimie Murgu Sq., 300041 Timișoara, Romania. E-mail: daninamuntean@umft.ro

\section{Introduction}

Chronic non-communicable pathologies, mainly cardiovascular and neurodegenerative diseases, cancer, and type 2 diabetes are nowadays the leading causes of mortality, being collectively responsible for almost $70 \%$ of deaths worldwide (WHO, 2017). Importantly, all lifestyle-related conditions (unhealthy diet, tobacco use, lack of physical activity and alcohol abuse), classic risk factors (obesity, dys/hyperlipidemia, and high blood glucose) and comorbidities (e.g. depression) associated with these pathologies negatively impact on cellular metabolism, including mitochondrial function (Arduino et al. 2013, Medina-Gomez 2012, Nicolson 2014, Ouyang et al. 2013).

More recently, mitochondria have emerged as acute contributors to both pathogenesis and ultimate outcome of acute severe conditions, such as sepsis, trauma and stroke (Arulkumaran et al. 2016, Busija et al. 
2016, Jang et al. 2017).

Tissue biopsy, although the most relevant method to confirm various pathological changes in diseased organs, implies high costs and is not feasible in all clinical conditions, especially those related to older individuals who cannot cooperate during the procedure or in the presence of hemostasis disorders (Tyrrell et al. 2016). On the other hand, circulating human blood cells such as peripheral blood mononuclear cells (PBMC) and platelets are increasingly used in translational research for the assessment of organ-specific mitochondrial dys/function relevant for the clinical outcome (Chacko et al. 2013, Hsiao and Hoppel 2018, Sjovall et al. 2013). These abundant, readily available samples, obtained through minimally invasive procedures are ideal tools that allow dynamic monitoring of mitochondrial status, view the possibility to perform serial measurements. Indeed, the impairment of mitochondrial respiration has emerged in the past decade as a disease biomarker and a quantification tool for the evaluation of disease prognosis and/or therapeutic response.

The occurrence of an energy crisis has been widely acknowledged as a central event in the pathophysiological sequence of common degenerative and metabolic pathologies that are nowadays viewed as "primarily systemic bioenergetic diseases" (Wallace 2013). In this respect, high-throughput assays have been developed and constantly improved in order to allow the assessment of the bioenergetic profile of blood cells as a mirror of the energetic capacity of body tissues (Chacko et al. 2014, Tyrrell et al. 2016). In particular, there is increasing evidence that measurement of platelet mitochondrial function can serve as a good proxy for tissue-specific defects in cellular respiration (Zharikov and Shiva 2013).

The aim of this mini review was to summarize current information in the field of platelet mitochondrial dysfunction in both acute and chronic pathologies.

\section{Search Strategy}

The PubMed data base was searched for English-language literature following MeSH (Medical Subject Headings): "peripheral platelets", "circulating blood platelets", "mitochondrial dysfunction", "mitochondrial respiration", "bioenergetics", "profile", "biomarker", "mechanism", "interaction, "correlation"', "human", "acute", "chronic", and "disease". All articles addressing the topic were studied in detail and additional relevant literature was extracted from the references of the cited papers. The "related articles" function on PubMed was also used to further identify relevant information. No publication date restrictions were applied.

\section{Platelet function regulation and mitochon- dria}

Platelets are short-lived (5-7 days), anucleated blood cells primarily involved in the regulation of hemostasis and thrombosis (Koupenova et al. 2018) that also play important roles in inflammation, immunity, and cancer (Li 2016, Rondina et al. 2013, Semple et al. 2011).

Despite having a relatively low number of functional mitochondria, platelets are highly energy consuming, metabolically active cells. Accordingly, the main role of platelet mitochondria is to provide the ATP required for their activation within the process of thrombus formation (Rendu and Brohard-Bohn 2001, Zharikov and Shiva 2013). Although platelets in basal state are powered by both oxidative phosphorylation and glycolysis, the former has been reported to be the prevalent source of energy when platelets are activated (Aibibula et al. 2018, Chacko et al. 2013). Platelets have a higher oxygen consumption rates as compared to leucocytes since higher levels of ATP are required for the normal functioning of ion channels that maintain the intracellular ionic balance (particularly of calcium ions) that is essential for preventing platelet activation in basal conditions (Kramer et al. 2014). Another important platelet trait is the fact that mitochondrial complex III and IV proteins are low (Kramer et al. 2014) which means that even a slight degree of mitochondrial damage could have a very severe impact on platelet function. Also, this feature serves to validate the important role of platelet mitochondrial respiration monitoring as a very useful, minimally invasive diagnostic and prognostic tool in widespread pathologies proven to affect mitochondrial complexes III and IV, such as diabetes (Raza et al. 2011), Alzheimer's disease (Parker et al. 1990b) or Parkinson's disease (Benecke et al. 1993, Haas et al. 1995).

In platelets, as in other cells, oxidative phosphorylation and glycolysis are inter-linked in such a way that a decrease/inhibition of one process leads to the compensatory increase of the other (Akkerman et al. 1979). It has been reported more than 2 decades ago that a significant increase in lactate production (a hallmark of 
basal glycolysis) secondary to the impairment of oxidative phosphorylation occurred in platelets isolated from elderly people (as compared to young individuals) suggesting that changes in peripheral blood cells reflect the ones reported in post-mitotic tissues with ageing (D'Aurelio et al. 2001). Also, since it is now clear that there is an age-related decline in platelet counts for both male and female patients (Mahlknecht and Kaiser 2010) it is tempting to assume that platelets with disrupted mitochondrial function, as reflected by the impaired oxidative phosphorylation, have a higher clearance than the healthy ones. Indeed, a direct link between excessive reactive oxygen species (ROS) generated by inadequate mitochondrial respiration and platelet apoptosis has been described, suggesting that human platelet senescence is at least in part mediated by mitochondrial dysfunction (Wang et al. 2017, Wang et al. 2015b).

There has been a debate about the roles of the two processes, oxidative phosphorylation or glycolysis, in platelet aggregation. While early studies supported the major role of the latter as the main source of energy (Chaudhry et al. 1973, Misselwitz et al. 1987), more recent ones concluded that ATP provided by mitochondrial oxidative phosphorylation plays the critical part (Barile et al. 2012, Yamagishi et al. 2001). Recent bioenergetic studies in intact platelets demonstrate that, upon thrombin stimulation, oxidative phosphorylation is rapidly engaged and the process is supported by both L-glutamine and fatty acids oxidation (Ravi et al. 2015). Moreover, in order to evaluate whether the inhibition of mitochondrial respiration can disrupt platelet function, several groups assessed the effects of various chemicals on the electron transport chain complexes. Thus, Barile et al. (2012) tested different heterocyclic compounds belonging to the tetrazole, thiazole and 1,2,3-triazole classes. These compounds were able to interfere with blood clotting, most probably via the inhibition of cytochrome oxidase. Tomasiak et al. (2004) also proved that impairment of mitochondrial complex III (cytochrome oxidase) by nitric oxide (NO) or mitochondrial complex IV reduced mitochondrial energy production, which in turn inhibited platelet aggregation and secretion, thus demonstrating that platelet-activated coagulation depends on adequate mitochondrial respiratory function.

However, mitochondria also regulate the activation of platelets during thrombogenesis via non-ATP-mediated mechanisms, such as the mild generation of signaling molecules including mitochondrial ROS or the increase in mitochondrial calcium (Pignatelli et al. 1998). Importantly, these pathways that can equally trigger platelet apoptosis when released in high amounts (Lebois and Josefsson 2016, Lopez et al. 2007) - Figure 1. Eukaryotic cells display a high efficiency of oxidative phosphorylation but this process inevitably leads to mitochondrial ROS release, thus rendering mitochondria as the main source of cellular ROS (Muntean et al. 2016). Complexes I and III of the electron transport chain also play a significant role in platelet ROS production as they generate the superoxide ion, which is then converted by superoxide dismutase (SOD) into hydrogen peroxide $\left(\mathrm{H}_{2} \mathrm{O}_{2}\right)$ (Pietraforte et al. 2014). These ROS are now recognized as second messengers in collagen-stimulated platelet activation (Zharikov and Shiva 2013). Indeed, exogenous treatment with $\mathrm{H}_{2} \mathrm{O}_{2}$ induces platelet activation while intracellular $\mathrm{H}_{2} \mathrm{O}_{2}$ scavenging inhibits calcium mobilization and platelet aggregation (Pignatelli et al. 1998). ROS production is regulated mainly by the redox state of the electron transport chain and therefore by the proton motive force/mitochondrial membrane potential $(\Delta \Psi)$ (Lambert and Brand 2004). In this regard, several studies demonstrated a link between hyperpolarization of the mitochondrial membrane, ROS production and platelet activation (Matarrese et al. 2009, Yamagishi et al. 2001). For example, platelets from patients with diabetes expressed a decreased rate of oxygen consumption together with hallmark signs of increased ROS production (Avila et al. 2012). Matarrese et al. (2009) demonstrated that an activator of the complement system can also induce membrane hyperpolarization, oxidative stress and platelet activation. Moreover, the group of Brownlee reported that hyperglycemia induces membrane hyperpolarization in healthy platelets, a process that increased ROS generation and elicited platelet activation (Yamagishi et al. 2001).

Apart from superoxide and $\mathrm{H}_{2} \mathrm{O}_{2}$, mitochondria are able to produce $\cdot \mathrm{NO}$ (Rusak et al. 2006). A rapid reaction between superoxide and NO leads to the formation of peroxynitrite $\left(\mathrm{ONOO}^{-}\right)$, a powerful oxidizing and nitrating compound. In collagen-stimulated platelets, $\mathrm{ONOO}^{-}$was reported to decrease ATP concentration and mitochondrial respiration via the inhibition of complexes I, II and IV of the respiratory chain (Rusak et al. 2006) Figure 1 (left dotted line). Moreover, the inhibitory effect observed on platelet secretion (but not on aggregation) may be due, at least in part, to the decrease of mitochondrial ATP production (Rusak et al. 2006). 

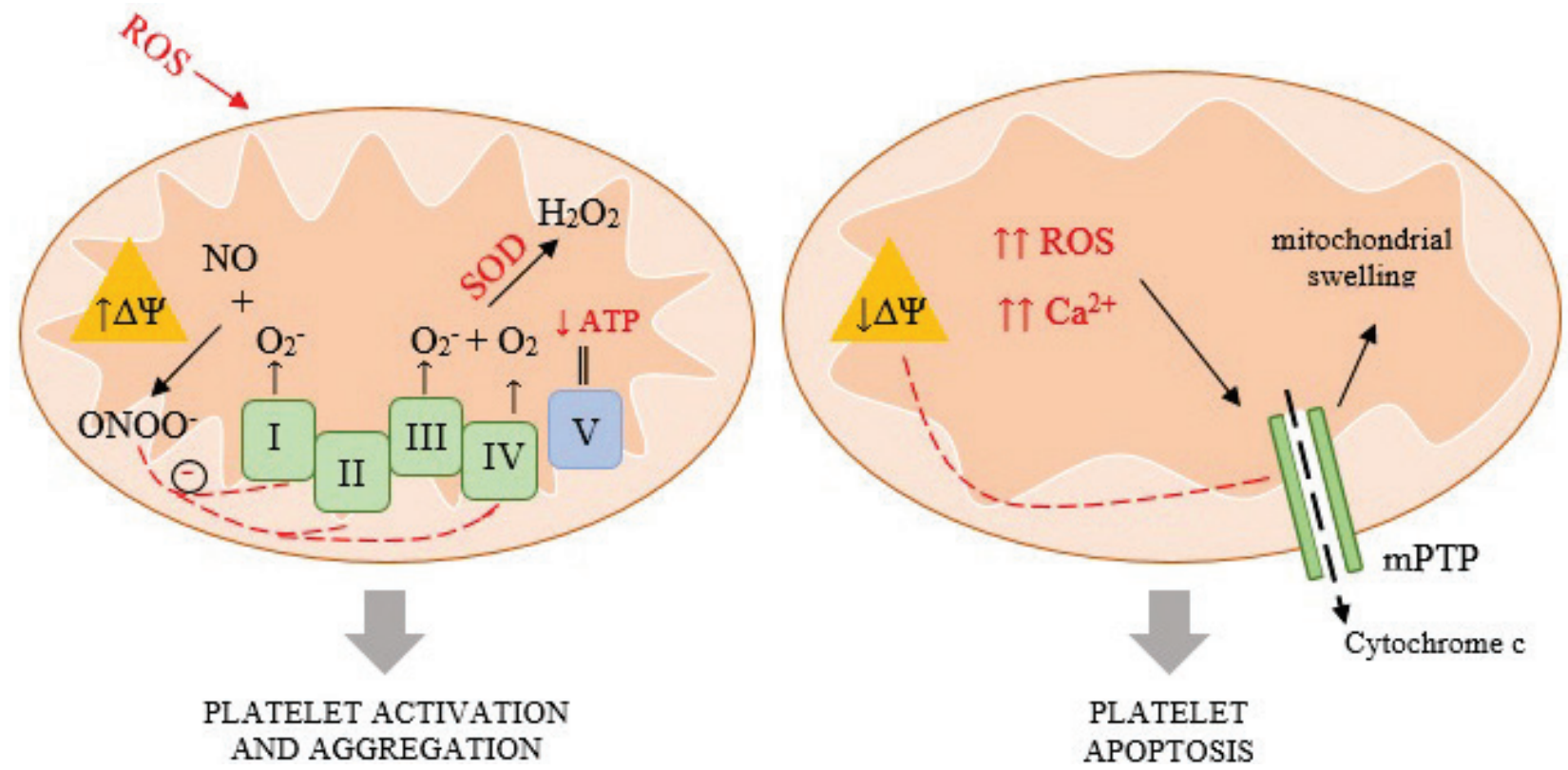

Fig. 1. Mitochondrial regulation of platelet function (explications in text).

Therefore, accumulating evidence suggests that platelet mitochondria are not limited to providing ATP from oxidative phosphorylation but that they play crucial roles in triggering platelet activation through many interlinked mitochondrial processes: $i)$ the increase in ROS production, caused by a dysfunctional electron transport chain; ii) the collapse of the mitochondrial membrane potential $(\Delta \Psi \mathrm{m})$ caused by the impaired proton shift towards the mitochondrial intermembrane space and iii) the opening of a "megachannel", the mitochondrial permeability transition pore (mPTP) (Hottz et al. 2013, Leytin et al. 2009, Lopez et al. 2007) by increased to ROS and ROS-induced calcium mobilization via phospholipase C activation (Pietraforte et al. 2014). Thus, a vicious circle is created, in which the decreased $\triangle \Psi \mathrm{m}$ opens the mPTP which will further reduce the mitochondrial membrane potential (Wang et al. 2017) Figure 1 - right. Several studies have demonstrated that mPTP opening is associated with an increase of the inner mitochondrial membrane permeability to different compounds (ions, protons, and small metabolites) that cause mitochondrial swelling and the consecutive collapse of the mitochondrial membrane potential which finally leads to ATP exhaustion and cell death (Bernardi et al. 2015, Ong et al. 2015). Apart from this, mPTP also seems to be an important determinant of platelet PS (phosphatidylserine) exposure to the plasma milieu, an event that holds an important place in normal homeostasis since it is involved in thrombin production regulation (Lentz 2003). Studies have demonstrated that in stimulated platelets, exposure of PS is closely linked to mPTP formation (Jobe et al. 2008, Remenyi et al. 2005), release of cytochrome $\mathrm{c}$ and subsequent apoptosis (Pietraforte et al. 2014). Elevated levels of cytoplasmic $\mathrm{Ca}^{2+}$ are a necessary but insufficient condition for an initial PS exposure signal; conversely, inhibition of mitochondrial $\mathrm{Ca}^{2+}$ entry abolishes elevation of mitochondrial $\mathrm{Ca}^{2+}$ levels along with $\mathrm{mPTP}$ formation and PS exposure but does not affect platelet granule release or aggregation (Choo et al. 2012).

Besides their physiological role in platelet plug formation within the process of primary hemostasis (Cimmino and Golino 2013), it has been shown that platelets can recruit leukocytes at the site of inflammation and/or vascular injury, with the subsequent release of several inflammatory mediators and angiogenic factors (Smyth et al. 2009). Moreover, since platelets express toll-like receptors on their surface that are able to recognize pathogen-associated molecular patterns, they also play a significant role as mediators of innate immune response against invading microorganisms (Aslam et al. 2006). Platelet activation also lead to the release of respiratory-competent mitochondria. Boudreau et al. (2014) demonstrated that these extracellular platelet mitochondria are key mediators in inflammatory conditions. When found in high amounts in platelet concentrates, extracellular mitochondria induce transfusion-related acute reactions (e.g. fever, skin manifestations, etc.). Also, due to the presence of mitochondrial $\mathrm{N}$-formylated peptides, leukocyte 
recruitment and neutrophil rolling along the vascular wall are promoted (Boudreau et al. 2014, Schiffmann et al. 1975). Owing to their ancestral bacterial origin, extracellular mitochondria serve as a substrate for the bactericidal sPLA2-IIA (secreted phospholipase A2-IIA), leading to mitochondrial integrity disruption and the release of ATP and mitochondrial DNA (mtDNA). Moreover, the interaction between mitochondria and sPLA2-IIA induces neutrophil activation and the formation of neutrophil extracellular traps (Boudreau et al. 2014) which in turn promotes platelet activation and aggregation (Fuchs et al. 2010, Gros et al. 2014); this might explain the long- time observed clinical link between sterile inflammation states (e.g. cancer) and thrombosis. It is important to mention that, since platelets lack nuclei. they also represent the ideal tool for future mtDNA studies aimed at anti-inflammatory therapeutic development (Wang et al. 2017).

As previously reported in the literature, not only thrombocytes but also leukocytes have been started to be used as biomarker of mitochondrial dysfunction in various pathologies such as neurodegenerative diseases, diabetes, cancer and cardiovascular pathologies (Briet et al. 2003, Clayton and Vinograd 1969, Cordero et al. 2010, Japiassu et al. 2011, Widlansky et al. 2010). Specifically, monocytes are considered a good sensor of metabolic stressors, such as hyperlipidemia or hyperglycemia. Also, lymphocytes bioenergetics can be used an index of disease processes that are associated with inflammation, as recently reviewed by Kramer et al. (2014).

\section{Methods used to assess respiratory mito- chondrial function in platelets}

A large number of studies have already shown that mitochondrial dysfunction is present in various frequent pathologies, such as diabetes (Duicu et al. 2016), cancer (Sturza et al. 2018), neurodegenerative pathologies (Nicolson 2014) and cardiovascular diseases, the most significant cause of morbidity and mortality globally in the last 15 years (World Health Organization, 2018). As previously stated, in such pathological settings the easily accessible platelets demonstrate the potential for being used as markers for disease monitoring and recovery after therapeutic interventions.

The investigation of maximal enzymatic activity of the respiratory chain complexes is a widespread spectrophotometric method used to assess mitochondrial function (Sjovall et al. 2013). However, the evaluation of isolated complex activity does not offer an accurate account on the global mitochondrial function because respiratory chain complexes are interdependent and work as a whole, regulating up-stream other enzymes and supercomplexes (Lenaz and Genova 2009). Therefore, in order to correctly analyze mitochondrial function, a technique that operates as close as possible to a physiological environment (such as platelet-rich plasma) and without or at least with a minimal cell disturbance should be used. Of note, assessment of platelet respiration can be traced back to the late $60 \mathrm{~s}$ (Kitchens and Newcomb 1968).

Nowadays high resolution respirometry using the Oxygraph-2K equipment (Oroboros Instr.), is widely used for the assessment of peripheral blood cells respiration, including platelets (Sjovall et al. 2010). The development of this equipment allows nowadays the study of either intact or permeabilized cells for which exogenous substrates, inhibitors or uncouplers can be added, in order to analyze mitochondrial function (Pesta and Gnaiger 2012, Sumbalová 2018).

There is an increasing interest of the research community in performing mitochondrial respiratory studies in blood cells yet standardization of the assays is still needed. This is one of the objectives of the COST Action CA15203 MITOEAGLE (MitoEAGLE 2018). The group of Eskil Elmer was among the first to attempt standardization of the assay. Currently, two consecutive centrifugations at room temperature are required to obtain platelet-rich plasma for respirometry studies (Sjovall et al. 2013). These researchers also evaluated the impact of whole blood storage at either room temperature or at $4{ }^{\circ} \mathrm{C}$ and found that respiration remained stable after $24 \mathrm{~h}$ but after $48 \mathrm{~h}$ platelet mitochondria showed reduced respiratory capacity. A decline of both mitochondrial respiration and platelet function with the storage was also demonstrated by other studies, platelet storage time being associated with an increase in proton leak, ROS production and platelet apoptosis (Perales Villarroel et al. 2013, Ravi et al. 2015). Further studies are required to address the effects of time of sampling, anticoagulants used, transportation, separation procedures etc. on platelet activation and how they will impact on respirometry studies.

Despite the fact that evidence points to the major role of oxidative phosphorylation in platelets, glycolysis remains also an important source of energy. The study of both processes is possibly by means of the extracellular flux analyzer (Agilent Seahorse Bioscience) that requires small numbers of intact cells to evaluate the oxygen consumption rate related to mitochondrial respiration as 
well as $\mathrm{pH}$ modifications ascribed to changes in the glycolytic process (Avila et al. 2012, Chacko et al. 2013, Kramer et al. 2014).

\section{Impairment of platelet mitochondrial function in particular diseases}

The process of collecting an appropriate amount of a viable tissue samples in systemic or organ-specific pathologies requires a high degree of invasiveness, thus the development of relevant cellular models to study mitochondrial function in humans is hindered. From this point of view, blood platelets are abundant and are easily obtainable through a simple blood draw, therefore they represent an attractive source for mitochondria studies in man (Zharikov and Shiva 2013). The study of platelet mitochondrial function in various disease states provides an effective way to investigate the underlying pathology. There is an abundance of literature demonstrating the association between platelet mitochondrial dysfunction and ageing/ageing-related diseases; therefore, platelet respirometry is viewed as a viable marker of systemic mitochondrial dysfunction (Hauptmann 2006, Sjovall et al. 2013, Sjovall et al. 2010). Besides, due to the lack of nuclei, metabolic alterations can be investigated without the transcriptional regulation interference.

Table 1 reviews several studies aimed at elucidating platelet mitochondrial function in acute and chronic pathologies together with the reported change in mitochondrial function.

Table 1. Mechanisms of platelet mitochondrial dysfunction in various pathologies.

\begin{tabular}{|c|c|c|c|}
\hline Pathologies & Special conditions & Mitochondrial functional changes & Reference \\
\hline \multicolumn{4}{|c|}{ ACUTE CONDITIONS } \\
\hline \multirow{3}{*}{ Sepsis } & & $\begin{array}{l}\text { Platelet mitochondrial uncoupling } \\
\text { Increased respiratory capacity }\end{array}$ & $\begin{array}{l}\text { Sjovall et al. } \\
2010\end{array}$ \\
\hline & & $\begin{array}{c}\text { Lower mitochondrial nicotinamide adenine } \\
\text { dinucleotide dehydrogenase (NADH) } \\
\text { Decreased CI, III and IV activity }\end{array}$ & $\begin{array}{l}\text { Protti et al. } \\
\quad 2015\end{array}$ \\
\hline & & $\begin{array}{l}\text { Non-survivors presented a higher basal and } \\
\text { maximal respiratory rate as compared to } \\
\text { survivors, rates associated with organ failure } \\
\text { and initial lactate level }\end{array}$ & $\begin{array}{l}\text { Puskarich et al. } \\
2016\end{array}$ \\
\hline Cardiac arrest & $\begin{array}{l}\text { Cardiac arrest induced } \\
\text { in a porcine model via } \\
\text { an asphyxia-associated } \\
\text { ventricular fibrillation }\end{array}$ & $\begin{array}{l}\text { Platelet mitochondrial bioenergetics are } \\
\text { correlated with cerebral bioenergetic function } \\
\text { Increase of CII-driven convergent respiration }\end{array}$ & $\begin{array}{l}\text { Ferguson et al } \text {. } \\
2016\end{array}$ \\
\hline Cardiogenic shock & & $\begin{array}{l}\text { Lower mitochondrial nicotinamide adenine } \\
\text { dinucleotide dehydrogenase (NADH) } \\
\text { Decreased CI, II, III and IV activity }\end{array}$ & $\begin{array}{l}\text { Protti et al. } \\
\quad 2015\end{array}$ \\
\hline
\end{tabular}

\section{CHRONIC CONDITIONS}

Ageing

A

Asthma

Pulmonary

hypertension
Decreased stability of CI

Decreased energy conservation

Decreased CIV activity

D'Aurelio et al. 2001

Asthmatic patients present increased oxygen utilization and efficient usage of substrates in platelets as previously shown in the airways

Weiling $\mathrm{Xu}$ 2015

Increased mitochondrial reserve capacity Increased CII activity
Nguyen et al. 2017 


\begin{tabular}{|c|c|c|c|}
\hline Dyslipidaemia & Treatment with statins & $\begin{array}{l}\text { Decreases ADP stimulated respiration } \\
\text { Decreases CI-linked respiration }\end{array}$ & $\begin{array}{l}\text { Vevera et al. } \\
\quad 2016\end{array}$ \\
\hline $\begin{array}{l}\text { Cardio-pulmonary } \\
\text { bypass }\end{array}$ & & Unchanged platelet mitochondrial function & $\begin{array}{l}\text { Mazzeffi et al. } \\
2016\end{array}$ \\
\hline Sickle cell disease & & $\begin{array}{l}\text { Decreased complex } \mathrm{V} \text { activity } \\
\text { Decreased mitochondrial respiration } \\
\text { Membrane hyperpolarization } \\
\text { Increased ROS production }\end{array}$ & $\begin{array}{l}\text { Cardenes et al. } \\
2014\end{array}$ \\
\hline $\begin{array}{l}\text { Bipolar affective } \\
\text { disorder }\end{array}$ & $\begin{array}{c}\text { Manic patients } \\
\text { Depressive patients } \\
\text { Patients in remission }\end{array}$ & $\begin{array}{l}\text { Increased CI-linked respiration } \\
\text { Decreased CIV activity } \\
\text { Increased CI-linked respiration }\end{array}$ & $\begin{array}{l}\text { Hroudová et al. } \\
\qquad 2019\end{array}$ \\
\hline Depression & Intact platelets & $\begin{array}{l}\text { Decreased physiological respiration, ETS } \\
\text { capacity and respiratory } \\
\text { rate after complex I inhibition } \\
\text { No changes in mitochondrial respiratory rates }\end{array}$ & $\begin{array}{l}\text { Hroudova et al. } \\
\qquad 2013\end{array}$ \\
\hline \multirow[t]{2}{*}{ Alzheimer's disease } & Intact platelets & $\begin{array}{l}\text { Decreased endogenous basal respiration rates, } \\
\text { C IV activity and ETS capacity, increased } \\
\text { respiratory rates after CI inhibition }\end{array}$ & $\begin{array}{l}\text { Parker et al. } \\
\text { 1990b } \\
\text { Mancuso et al. } \\
2003\end{array}$ \\
\hline & Permeabilized platelets & $\begin{array}{l}\text { Mitochondrial respiration was completely } \\
\text { rescued by the addition of } \mathrm{CI} \text { substrates }\end{array}$ & $\begin{array}{l}\text { Fisar et al. } \\
\quad 2016\end{array}$ \\
\hline Parkinson's disease & & $\begin{array}{c}\text { Mild CI defect } \\
\text { Decreased CI and CIV activity } \\
\text { Decreased CI and CII/III activity }\end{array}$ & $\begin{array}{c}\text { (Krige et al. } \\
\text { 1992) } \\
\text { (Benecke et al. } \\
\text { 1993) } \\
\text { (Haas et al. } \\
\text { 1995) }\end{array}$ \\
\hline $\begin{array}{l}\text { Huntington's } \\
\text { disease }\end{array}$ & & $\begin{array}{l}\text { Decreased CI activity } \\
\text { Decreased mitochondrial CI and CII function, } \\
\text { lower maximal phosphorylation capacity }\end{array}$ & $\begin{array}{c}\text { (Parker } \text { et al. } \\
\quad \text { 1990a) } \\
\text { (Ehinger 2016) }\end{array}$ \\
\hline Schizophrenia & $\begin{array}{l}\text { High positive } \\
\text { schizophrenics } \\
\text { Low positive } \\
\text { schizophrenics }\end{array}$ & No changes in CI activity & $\begin{array}{l}\text { (Ben-Shachar } \\
\text { et al. 2007) }\end{array}$ \\
\hline $\begin{array}{l}\text { Amyotrophic lateral } \\
\text { sclerosis }\end{array}$ & & Decreased CIV activity & $\begin{array}{l}\text { (Ehinger et al. } \\
\text { 2015) }\end{array}$ \\
\hline
\end{tabular}

\section{Platelet mitochondrial function in diabetes mellitus}

Cardiovascular disease (CVD) remains the world's most common cause of death with more than 17 millions annual global deaths (Roth et al. 2017).
Moreover, CVD is the most common comorbidity in type 2 diabetes mellitus (DM); overall CVD affects approximately $1 / 3$ of diabetic patients and accounts for approximately $1 / 2$ of all deaths (Einarson et al. 2018). Several factors such as endothelial dysfunction, oxidative stress, increased coagulability and chronic inflammation 
are direct contributors to the development of CVD (Leon and Maddox 2015). As presented above, besides their central role in coagulation, platelets are involved in inflammation, due to their ability to secrete several mediators, with the acceleration of both atherogenesis and progression towards diabetic micro- and macroangiopathy (Siewiera et al. 2016, Vieira-de-Abreu et al. 2012). Currently, it is widely known that atherosclerosis is the most frequent complication of both type 1 and 2 DM (Ersoy et al. 2015, Tomkin and Owens 2015) and platelet dysfunction is contributing to the occurrence of cardiovascular complications (Tomkin and Owens 2015). Nevertheless, there are rather few studies that comprehensively aimed at elucidating the role of platelet mitochondrial dys/function in DM (Tschoepe et al. 1991). Brownlee stated already back to (Brownlee 2001) that mitochondrial dysfunction can be at the root of pathomechanisms by which hyperglycemia causes diabetic complications. Moreover, it has been reported that a high concentration of glucose can induce mitochondrial damage in heart muscle fibres, skeletal muscle, brain and kidney tissue (Chowdhury et al. 2011) and therefore, the hypothesis of platelet mitochondrial dysfunction in high glucose conditions is conceivable. Indeed, $\mathrm{Wu}$ et al. (2015) demonstrated platelet mitochondrial changes such as swollen mitochondria with damaged inner membrane, an increased ROS production and a decreased ATP content in diabetic rats and patients, concluding that platelets can be used as a model to further analyze the changes of mitochondrial function in DM complications (Wu et al. 2015). Similarly, Siewiera et al. (2016) showed that untreated DM produces an increase of the mitochondrial mass and also changes in the bioenergetic profile of platelets by hyperpolarization of the mitochondrial membrane. At variance, other studies found no differences in platelet size/volume between type $2 \mathrm{DM}$ and healthy patients (Schaeffer $e t$ al. 1999). Also, non-proliferative diabetic retinopathy seems to hamper platelet submitochondrial particles membrane fluidity and to increase F0/F1-ATPase hydrolytic activity, both of which being recognized markers of mitochondrial dysfunction (Rodriguez-Carrizalez et al. 2014). Regarding the role of mitochondria in DM as sources of ROS, Fink et al. (2012) suggested that acute or chronic exposure of isolated human platelets to high glucose concentrations does not accelerate the mitochondrial oxidative metabolism and hence, the probability of an enhanced ROS production/altered redox status. However, several studies have shown that, apart from its ability to potentiate collagen-mediated platelet activation, hyperglycemia leads to increased ROS production and that ROS scavengers could prevent platelet hypersensitivity caused by activation (Yamagishi et al. 2001, Wu et al. 2015, Wang et al. 2017). Two antidiabetic drugs, metformin and phenformin (the latter being withdrawn due to an increased incidence of lactic acidosis) were tested on isolated platelets from healthy volunteers; respirometry results revealed that both compounds inhibit mitochondrial respiration via a complex I defect (Piel et al. 2015). As a consequence of this inhibition, ATP production was reduced, the enzyme AMP-activated protein kinase (AMPK) was activated, whereas the glucose turnover was accelerated via an increased glycolysis (Piel et al. 2015). In addition, mitochondrial inhibition was considered a direct consequence of lactic acidosis in patients treated with phenformin (Piel et al. 2015).

\section{Platelet mitochondrial function in cancer}

The development of cancer-specific therapies is the current aim of numerous research studies. In the past decade, as we attained new insights into cancer cells, mitochondria have emerged as key players of cell survival and growth signaling pathways as well as chemotherapy-induced apoptosis. It is now a known fact that mitochondria are effectors of cell death by being involved in the regulation of the intrinsic and extrinsic apoptotic pathway, the autophagic cell death pathway and the necrotic pathway - for a comprehensive review the reader is referred to the paper by Giorgi et al. (2008). Nowadays, scientists have proposed several mechanisms by which the Warburg effect observed in cancer cells (i.e. the shift of cancer cells to a high rate of glycolysis even if oxygen is in a high concentration) can take place. The proposed mechanisms include: i) mitochondrial dysfunction that leads to a decrease in ATP production; ii) adaptation of cancer cells to hypoxia; iii) interference of oncogenes with mitochondrial function; iv) a high upregulation of enzymes and glycolysis processes by cancer cells; and v) mtDNA mutations that can either increase ROS production and tumour proliferation or the adaptation of cancer cells to new environments (reviewed in Kroemer 2006).

The role of platelets in cancer is partially elucidated. It is known that platelets work in favor of cancer progression being involved in crucial steps of cancer evolution such as angiogenesis (by releasing both 
pro-angiogenic and anti-angiogenic regulators), cancer invasion (by releasing factors that control vessel permeability), tumor growth (by releasing growth factors), and cancer cell adhesion (by forming plateletcancer cell conjugates) that facilitate cancer metastasis (Li 2016). Moreover, cancer itself seems to induce platelet activation via the release of platelet-activating factors like thromboxane A2, ADP and thrombin (Li 2016).

In patients with ovarian cancer, (Wang et al. 2015a) observed a significant difference in platelet mitochondria and microtubule system when compared to healthy donors. Thus, cancer patients had $50 \%$ more platelets mitochondria as compared to healthy donors and these organelles occupied a larger part of the platelet area. When doxorubicin, a chemotherapeutic agent that has thrombocytopenic side-effects, was tested on platelet function, it was found that the drug dose-dependently impaired platelet adhesion and aggregation, induced mitochondrial-mediated apoptosis via the intrinsic pathway, and increased mitochondrial ROS generation (Wang et al. 2015b). Interestingly, these effects were prevented by a mitochondrial selective ROS scavenger, an observation which stresses once more mitochondrial ROS are key players in platelet apoptosis and mitochondrial ROS scavengers are potential therapeutic agents in platelet-associated disorders that also involve mitochondrial oxidative damage, respectively (Wang et al. 2015b). Several studies reported on the effects of various compounds to induce platelet apoptosis via the mitochondria pathway. Another chemotherapeutic drug, cisplatin, increased ROS production, induced the mitochondrial translocation of the proapoptotic Bax with subsequent mitochondrial membrane depolarization (Thushara et al. 2015). Of note, two of increasingly used supplements, resveratrol and melatonin, were reported to also induce platelet apoptosis via Bax translocation into mitochondria, increase cytochrome c release and caspase-3 activation (Thushara et al. 2015).

\section{Platelet mitochondrial function in hematolo- gic malignancies}

Hematologic malignancies (HM) are tumours of hematopoietic and lymphoid tissues that include leukemias, lymphomas, and plasma cell neoplasms (multiple myeloma). Even though the general tendency of HM survival rates has slightly increased over the past decade due to treatment advances (Dunham-Snary et al.
2014), these diseases represent the fourth most common type of cancer in both male and female populations (Caimari et al. 2010). In this context, a biomarker that can be correlated with the evolution, progression, severity and treatment response, might be advantageous in HM monitoring and therapy.

Mitochondrial dysfunction has been reported to play a critical role in the development and progression of HM, especially in leukemias where various mtDNA alterations (of mitochondrial-encoded cytochrome b, cytochrome c, COX-I and COX-II genes) were described - reviewed by (Sternfeld et al. 2009). Schimmer and Skrtic (2012) showed that in leukemic cells a significant increase of mitochondrial mass accompanied by a higher rate of oxygen consumption, as compared to normal cells occur. Moreover, at variance from other neoplasias, in acute myeloid leukemia cancer cells are more dependent on oxidative phosphorylation than on glycolysis (Ferguson et al. 2016, Ehinger et al. 2016). Interestingly, in both leukemia and lymphoma cells it was demonstrated that a mitochondrial respiratory defect exhibits a survival advantage (Puskarich et al. 2016). The mitochondrial uncoupling process (the disruption between substrate oxidation and ADP phosphorylation into ATP) has also been reported in leukemia cell, where it supports a shift to oxidation of fatty acids with increased resistance to the intrinsic apoptosis pathway (Xu et al. 2015).

In a recent pilot study we aimed at assessing the respiratory function of platelets isolated from patients with a number HM (non-Hodgkin lymphoma, acute myeloid leukemia, chronic lymphocytic leukemia). A significant decrease of all respiratory parameters in the HM group vs. control was found; a decrease of $80 \%$ for OXPHOS, $81 \%$ for State 2 and $75 \%$ for State 4 were recorded (unpublished data). These preliminary results clearly suggest that platelet mitochondrial function is impaired in patients with HM and further studies are mandatory to dynamically assess these parameters and their correlations with the prognostic, severity, survival rate and treatment response.

\section{Platelet mitochondrial function in neurode- generative disorders}

The literature review shows that mitochondrial dysfunction is involved in neurodegenerative diseases, such as Parkinson's disease (PD), Alzheimer's disease (AD), Huntington's disease (HD) and amyotrophic lateral 
sclerosis (ALS), disorders characterized by a gradual and selective loss of related neuronal system (DiMauro and Schon 2008, Lin and Beal 2006, Reddy 2008). As neurons have a high-energy demand, they rely on mitochondria for a proper function, thus being sensitive to every mitochondrial dysfunction. Neuronal damage and/or death can occur as a consequence of mitochondrial dysfunction via apoptosis, excitotoxicity, ETC abnormalities and increased ROS production, that can alter mitochondrial ATP production, calcium homeostasis, mitochondrial membrane potential and the opening of mPTP (Dong et al. 2009, Emerit et al. 2004, Rao et al. 2014, Schapira 1993).

A crucial finding in the assessment of mitochondrial function in patients with neurodegenerative disorders was made by studies that revealed that blood cells can recapitulate the mitochondrial alterations present in the central nervous system (Parker et al. 1989, Schapira 1993). Accordingly, it was firstly reported that patients with Parkinson's disease presented a complex I deficiency in both mitochondria from substantia nigra and platelets, respectively (Parker et al. 1989, Schapira 1993). Low complex I, complex II/III and complex IV activities in platelets from Parkinson's disease patients were described by Benecke et al. (1993) and Haas et al. (1995), respectively. Interestingly, Bronstein et al. (2015) found no impairments of ETC activity in PD patients. In Alzheimer disease, researchers found a decreased activity of complex IV (Mancuso et al. 2003, Parker et al. 1989) and later, also in complex III (Valla et al. 2006). A more recent study reported besides a decreased activity of complex IV, a low concentration of coenzyme Q10 in blood and an increased activity of complex I in platelets isolate from patients with $\mathrm{AD}$ (Fisar et al. 2016). In platelets from ALS patients, complex IV activity was also decreased, accompanied by a compensatory increase in cellular mitochondrial content (Ehinger et al. 2015). In
HD, studies yielded unclear results. Accordingly, Powers et al. (2007) found no significant difference in complex I or complex I/III activities in these patients, while a more recent study by Ehinger et al. (2016), revealed a decreased function of complex I, but this result was not uniformly confirmed.

Albeit a straightforward relationship between mitochondrial respiration and the pathogenesis of these disorders is lacking, assessment of platelet respiration has emerged as a putative biomarker in these pathologies as well.

\section{Conclusions}

An increasing number of studies are currently focused on mitochondrial dysfunction in disease, as they emerged a key organelles at the crossroad between health and disease and valuable tools for drug development. Due to their content of functional mitochondria, platelets are considered to be an easily accessible and reliable source for the assays aimed at evaluating mitochondrial dys/function in various pathologies. Assessment of mitochondrial platelet respiration has emerged as a minimally invasive tool able to provide insights about the systemic mitochondrial function. Future studies are required for the standardization of the assays using platelets as a substitute to characterize organ mitochondrial function in various pathologies.

\section{Conflict of Interest}

There is no conflict of interest.

\section{Acknowledgements}

This work was supported by the university grant PII-C4TC-2016 (A.P.). D.M.M is a member of the COST Action CA15203 - MITOEAGLE.

\section{References}

AIBIBULA M, NASEEM KM, STURMEY RG: Glucose metabolism and metabolic flexibility in blood platelets. J Thromb Haemost 16: 2300-2314, 2018.

AKKERMAN JW, HOLMSEN H, LOUGHNANE M: Simultaneous measurement of aggregation, secretion, oxygen uptake, proton production, and intracellular metabolites in the same platelet suspension. Anal Biochem 97: 387-393, 1979.

ARDUINO DM, ESTEVES AR, CARDOSO SM: Mitochondria drive autophagy pathology via microtubule disassembly: a new hypothesis for Parkinson disease. Autophagy 9: 112-114, 2013. 
ARULKUMARAN N, DEUTSCHMAN CS, PINSKY MR, ZUCKERBRAUN B, SCHUMACKER PT, GOMEZ H, GOMEZ A, MURRAY P, KELLUM JA, WORKGROUP AX: Mitochondrial function in sepsis. Shock 45 : 271-281, 2016.

ASLAM R, SPECK ER, KIM M, CROW AR, BANG KW, NESTEL FP, NI H, LAZARUS AH, FREEDMAN J, SEMPLE JW: Platelet toll-like receptor expression modulates lipopolysaccharide-induced thrombocytopenia and tumor necrosis factor-alpha production in vivo. Blood 107: 637-641, 2006.

AVILA C, HUANG RJ, STEVENS MV, APONTE AM, TRIPODI D, KIM KY, SACK MN: Platelet mitochondrial dysfunction is evident in type 2 diabetes in association with modifications of mitochondrial anti-oxidant stress proteins. Exp Clin Endocrinol Diabetes 120: 248-251, 2012.

BARILE CJ, HERRMANN PC, TYVOLL DA, COLLMAN JP, DECREAU RA, BULL BS: Inhibiting plateletstimulated blood coagulation by inhibition of mitochondrial respiration. Proc Natl Acad Sci U S 109 : 2539-2543, 2012.

BEN-SHACHAR D, BONNE O, CHISIN R, KLEIN E, LESTER H, AHARON-PERETZ J, YONA I, FREEDMAN N: Cerebral glucose utilization and platelet mitochondrial complex I activity in schizophrenia: A FDG-PET study. Prog Neuropsychopharmacol Biol Psychiatry 31: 807-813, 2007.

BENECKE R, STRUMPER P, WEISS H: Electron transfer complexes I and IV of platelets are abnormal in Parkinson's disease but normal in Parkinson-plus syndromes. Brain 116: 1451-1463, 1993.

BERNARDI P, RASOLA A, FORTE M, LIPPE G: The mitochondrial permeability transition pore: Channel formation by F-ATP synthase, integration in signal transduction, and role in pathophysiology. Physiol Rev 95 : 1111-1155, 2015.

BOUDREAU LH, DUCHEZ AC, CLOUTIER N, SOULET D, MARTIN N, BOLLINGER J, PARE A, ROUSSEAU M, NAIKA GS, LEVESQUE T, LAFLAMME C, MARCOUX G, LAMBEAU G, FARNDALE RW, POULIOT M, HAMZEH-COGNASSE H, COGNASSE F, GARRAUD O, NIGROVIC PA, GUDERLEY H, LACROIX S, THIBAULT L, SEMPLE JW, GELB MH, BOILARD E: Platelets release mitochondria serving as substrate for bactericidal group IIA-secreted phospholipase A2 to promote inflammation. Blood 124: 2173-2183, 2014.

BRIET F, TWOMEY C, JEEJEEBHOY KN: Relationship between metabolism and peripheral blood mononuclear cell mitochondrial complex I activity before and after a short-term refeeding in weight-losing cancer patients. Clin Nutr 22: 247-253, 2003.

BRONSTEIN JM, PAUL K, YANG L, HAAS RH, SHULTS CW, LE T, RITZ B: Platelet mitochondrial activity and pesticide exposure in early Parkinson's disease. Mov Disord 30: 862-866, 2015.

BROWNLEE M: Biochemistry and molecular cell biology of diabetic complications. Nature 414: 813-820, 2001.

BUSIJA DW, RUTKAI I, DUTTA S, KATAKAM PV: Role of mitochondria in cerebral vascular function: energy production, cellular protection, and regulation of vascular tone. Compr Physiol 6: 1529-1548, 2016.

CAIMARI A, OLIVER P, KEIJER J, PALOU A: Peripheral blood mononuclear cells as a model to study the response of energy homeostasis-related genes to acute changes in feeding conditions. OMICS 14: 129-141, 2010.

CARDENES N, COREY C, GEARY L, JAIN S, ZHARIKOV S, BARGE S, NOVELLI EM, SHIVA S: Platelet bioenergetic screen in sickle cell patients reveals mitochondrial complex $\mathrm{V}$ inhibition, which contributes to platelet activation. Blood 123: 2864-2872, 2014.

CHACKO BK, KRAMER PA, RAVI S, BENAVIDES GA, MITCHELL T, DRANKA BP, FERRICK D, SINGAL AK, BALLINGER SW, BAILEY SM, HARDY RW, ZHANG J, ZHI D, DARLEY-USMAR VM: The Bioenergetic Health Index: a new concept in mitochondrial translational research. Clin Sci (Lond) 127: 367-373, 2014.

CHACKO BK, KRAMER PA, RAVI S, JOHNSON MS, HARDY RW, BALLINGER SW, DARLEY-USMAR VM: Methods for defining distinct bioenergetic profiles in platelets, lymphocytes, monocytes, and neutrophils, and the oxidative burst from human blood. Lab Invest 93: 690-700, 2013.

CHAUDHRY AA, SAGONE AL, JR, METZ EN, BALCERZAK SP: Relationship of glucose oxidation to aggregation of human platelets. Blood 41: 249-258, 1973. 
CHOO HJ, SAAFIR TB, MKUMBA L, WAGNER MB, JOBE SM: Mitochondrial calcium and reactive oxygen species regulate agonist-initiated platelet phosphatidylserine exposure. Arterioscler Thromb Vasc Biol 32: 2946-2955, 2012.

CHOWDHURY SK, DOBROWSKY RT, FERNYHOUGH P: Nutrient excess and altered mitochondrial proteome and function contribute to neurodegeneration in diabetes. Mitochondrion 11: 845-854, 2011.

CIMMINO G, GOLINO P: Platelet biology and receptor pathways. J Cardiovasc Transl Res 6: 299-309, 2013.

CLAYTON DA, VINOGRAD J: Complex mitochondrial DNA in leukemic and normal human myeloid cells. Proc Natl Acad Sci US A 62: 1077-1084, 1969.

CORDERO MD, DE MIGUEL M, MORENO FERNÁNDEZ AM, CARMONA LÓPEZ IM, GARRIDO MARAVER J, COTAN D, GÓMEZ IZQUIERDO L, BONAL P, CAMPA F, BULLON P, NAVAS P, SÁNCHEZ ALCÁZAR JA: Mitochondrial dysfunction and mitophagy activation in blood mononuclear cells of fibromyalgia patients: implications in the pathogenesis of the disease. Arthritis Res Ther 12: R17, 2010.

D'AURELIO M, MERLO PICH M, CATANI L, SGARBI GL, BOVINA C, FORMIGGINI G, PARENTI CASTELLI G, BAUM H, TURA S, LENAZ G: Decreased Pasteur effect in platelets of aged individuals. Mech Ageing Dev 122: 823-833, 2001.

DIMAURO S, SCHON EA: Mitochondrial disorders in the nervous system. Annu Rev Neurosci 31: 91-123, 2008.

DONG XX, WANG Y, QIN ZH: Molecular mechanisms of excitotoxicity and their relevance to pathogenesis of neurodegenerative diseases. Acta Pharmacol Sin 30: 379-387, 2009.

DUICU OM, LIGHEZAN R, STURZA A, BALICA R, VADUVA A, FEIER H, GASPAR M, IONAC A, NOVEANU L, BORZA C, MUNTEAN DM, MORNOS C: Assessment of mitochondrial dysfunction and monoamine oxidase contribution to oxidative stress in human diabetic hearts. Oxid Med Cell Longev 2016: 8470394, 2016.

DUNHAM-SNARY KJ, SANDEL MW, WESTBROOK DG, BALLINGER SW: A method for assessing mitochondrial bioenergetics in whole white adipose tissues. Redox Biol 2: 656-660, 2014.

EHINGER JK, MOROTA S, HANSSON MJ, PAUL G, ELMER E: Mitochondrial dysfunction in blood cells from amyotrophic lateral sclerosis patients. J Neurol 262: 1493-1503, 2015.

EHINGER JK, MOROTA S, HANSSON MJ, PAUL G, ELMER E: Mitochondrial respiratory function in peripheral blood cells from Huntington's disease patients. Mov Disord Clin Pract 3: 472-482, 2016.

EINARSON TR, ACS A, LUDWIG C: Prevalence of cardiovascular disease in type 2 diabetes: a systematic literature review of scientific evidence from across the world in 2007-2017. Cardiovasc Diabetol 17: 83, 2018.

EMERIT J, EDEAS M, BRICAIRE F: Neurodegenerative diseases and oxidative stress. Biomed Pharmacother 58: 39-46, 2004.

ERSOY M, SELCUK DURU HN, ELEVLI M, ERSOY O, CIVILIBAL M: Aortic intima-media thickness and mean platelet volume in children with type 1 diabetes mellitus. Iranian J Pediatr 25: e368, 2015.

FERGUSON MA, SUTTON RM, KARLSSON M, SJÖVALL F, BECKER LB, BERG RA, MARGULIES SS, KILBAUGH TJ: Increased platelet mitochondrial respiration after cardiac arrest and resuscitation as a potential peripheral biosignature of cerebral bioenergetic dysfunction. J Bioenerg Biomembr 48: 269-279, 2016.

FINK BD, HERLEIN JA, O'MALLEY Y, SIVITZ WI: Endothelial cell and platelet bioenergetics: effect of glucose and nutrient composition. PloS One 7: e39430, 2012.

FISAR Z, HROUDOVA J, HANSIKOVA H, SPACILOVA J, LELKOVA P, WENCHICH L, JIRAK R, ZVEROVA M, ZEMAN J, MARTASEK P, RABOCH J: Mitochondrial respiration in the platelets of patients with Alzheimer's disease. Curr Alzheimer Res 13: 930-941, 2016.

FUCHS TA, BRILL A, DUERSCHMIED D, SCHATZBERG D, MONESTIER M, MYERS DD JR, WROBLESKI SK, WAKEFIELD TW, HARTWIG JH, WAGNER DD: Extracellular DNA traps promote thrombosis. Proc Natl Acad Sci U S A 107: 15880-15885, 2010.

GIORGI C, ROMAGNOLI A, PINTON P, RIZZUTO R: Ca2+ signaling, mitochondria and cell death. Curr Mol Med 8: 119-130, 2008.

GROS A, OLLIVIER V, HO-TIN-NOÉ B: Platelets in inflammation: regulation of leukocyte activities and vascular repair. Front Immunol 5: 678, 2014.

HAAS RH, NASIRIAN F, NAKANO K, WARD D, PAY M, HILL R, SHULTS CW: Low platelet mitochondrial complex I and complex II/III activity in early untreated Parkinson's disease. Ann Neurol 37: 714-722, 1995. 
HAUPTMANN S, KEIL U, SCHERPING I, BONERT A, ECKERT A, MULLER WE: Mitochondrial dysfunction in sporadic and genetic Alzheimer's disease. Exp Gerontol 41: 668-673, 2006.

HOTTZ ED, OLIVEIRA MF, NUNES PC, NOGUEIRA RM, VALLS-DE-SOUZA R, DA POIAN AT, WEYRICH AS, ZIMMERMAN GA, BOZZA PT, BOZZA FA: Dengue induces platelet activation, mitochondrial dysfunction and cell death through mechanisms that involve DC-SIGN and caspases. J Thromb Haemost 11: 951-962, 2013.

HROUDOVA J, FISAR Z, HANSIKOVA H, KALISOVA L, KOTZLEROVA E, ZVEROVA M, LAMBERTOVA A, RABOCH J: Mitochondrial dysfunction in blood platelets of patients with manic episode of bipolar disorder. CNS Neurol Disord Drug Targets 18: 222-223, 2019

HROUDOVA J, FISAR Z, KITZLEROVA E, ZVEROVA M, RABOCH J: Mitochondrial respiration in blood platelets of depressive patients. Mitochondrion 13: 795-800, 2013.

HSIAO CP, HOPPEL C: Analyzing mitochondrial function in human peripheral blood mononuclear cells. Anal Biochem 549: 12-20, 2018.

JANG DH, GREENWOOD JC, SPYRES MB, ECKMANN DM: Measurement of mitochondrial respiration and motility in acute care: sepsis, trauma, and poisoning. J Intensive Care Med 32: 86-94, 2017.

JAPIASSÚ AM, SANTIAGO AP, D'AVILA JC, GARCIA-SOUZA LF, GALINA A, CASTRO FARIA-NETO HC, BOZZA FA, OLIVEIRA MF: Bioenergetic failure of human peripheral blood monocytes in patients with septic shock is mediated by reduced F1Fo adenosine-5'-triphosphate synthase activity. Crit Care Med 39: 1056-1063, 2011.

JOBE SM, WILSON KM, LEO L, RAIMONDI A, MOLKENTIN JD, LENTZ SR, Di PAOLA J: Critical role for the mitochondrial permeability transition pore and cyclophilin D in platelet activation and thrombosis. Blood 111: 1257-1265, 2008.

EHINGER JK, MOROTA S, HANSSON MJ, PAUL G, ELMÉR E: Mitochondrial respiratory function in peripheral blood cells from Huntington's disease patients. Mov Disord Clin Pract 3: 472-482, 2016.

KOUPENOVA M, CLANCY L, CORKREY HA, FREEDMAN JE: Circulating platelets as mediators of immunity, inflammation, and thrombosis. Circ Res 122: 337-351, 2018.

KRAMER PA, RAVI S, CHACKO B, JOHNSON MS, DARLEY-USMAR VM: A review of the mitochondrial and glycolytic metabolism in human platelets and leukocytes: implications for their use as bioenergetic biomarkers. Redox Biol 2: 206-210, 2014.

KRIGE D, CARROLL MT, COOPER JM, MARSDEN CD, SCHAPIRA AH: Platelet mitochondrial function in Parkinson's disease. The Royal Kings and Queens Parkinson Disease Research Group. Ann Neurol 32: 782-788, 1992.

KROEMER G: Mitochondria in cancer. Oncogene 25: 4630-4632, 2006.

LAMBERT AJ, BRAND MD: Inhibitors of the quinone-binding site allow rapid superoxide production from mitochondrial NADH:ubiquinone oxidoreductase (complex I). J Biol Chem 279: 39414-39420, 2004.

LEBOIS M, JOSEFSSON EC: Regulation of platelet lifespan by apoptosis. Platelets 27: 497-504, 2016.

LENAZ G, GENOVA ML: Structural and functional organization of the mitochondrial respiratory chain: a dynamic super-assembly. Int J Biochem Cell Biol 41: 1750-1772, 2009.

LENTZ BR: Exposure of platelet membrane phosphatidylserine regulates blood coagulation. Prog Lipid Res 42 : 423-438, 2003.

LEON BM, MADDOX TM: Diabetes and cardiovascular disease: Epidemiology, biological mechanisms, treatment recommendations and future research. World J Diabetes 6: 1246-1258, 2015.

LEYTIN V, ALLEN DJ, MUTLU A, GYULKHANDANYAN AV, MYKHAYLOV S, FREEDMAN J: Mitochondrial control of platelet apoptosis: effect of cyclosporin A, an inhibitor of the mitochondrial permeability transition pore. Lab Invest 89: 374-384, 2009.

LI N: Platelets in cancer metastasis: To help the "villain" to do evil. Int J Cancer 138: 2078-2087, 2016.

LIN MT, BEAL MF: Mitochondrial dysfunction and oxidative stress in neurodegenerative diseases. Nature 443: 787-795, 2006.

LOPEZ JJ, SALIDO GM, GOMEZ-ARTETA E, ROSADO JA, PARIENTE JA: Thrombin induces apoptotic events through the generation of reactive oxygen species in human platelets. J Thromb Haemost 5: 1283-1291, 2007. 
MAHLKNECHT U, KAISER S: Age-related changes in peripheral blood counts in humans. Exp Ther Med 1: 1019-1025, 2010.

MANCUSO M, FILOSTO M, BOSETTI F, CERAVOLO R, ROCCHI A, TOGNONI G, MANCA ML, SOLAINI G, SICILIANO G, MURRI L: Decreased platelet cytochrome c oxidase activity is accompanied by increased blood lactate concentration during exercise in patients with Alzheimer disease. Exp Neurol 182: 421-426, 2003.

MATARRESE P, STRAFACE E, PALUMBO G, ANSELMI M, GAMBARDELLA L, ASCIONE B, DEL PRINCIPE D, MALORNI W: Mitochondria regulate platelet metamorphosis induced by opsonized zymosan A--activation and long-term commitment to cell death. FEBS J 276: 845-856, 2009.

MAZZEFFI M, LUND L, WALLACE K, HERRERA AV, TANAKA K, ODONKOR P, STRAUSS E, ROCK P, FISKUM G: Effect of cardiopulmonary bypass on platelet mitochondrial respiration and correlation with aggregation and bleeding: a pilot study. Perfusion 31: 508-515, 2016.

MEDINA-GOMEZ G: Mitochondria and endocrine function of adipose tissue. Best Pract Res Clin Endocrinol Metab 26: 791-804, 2012.

MISSELWITZ F, LEYTIN VL, REPIN VS: Effect of metabolic inhibitors on platelet attachment, spreading and aggregation on collagen-coated surfaces. Thromb Res 46: 233-240, 1987.

MITOEAGLE: An interlaboratory guide through procedures for mitochondrial respiratory studies with intact and permeabilized peripheral blood mononuclear cells and platelets (MS under preparation at the address http://www.mitoeagle.org/index.php/MitoEAGLE_blood_cells_1). 2018.

MUNTEAN DM, STURZA A, DANILA MD, BORZA C, DUICU OM, MORNOS C: The role of mitochondrial reactive oxygen species in cardiovascular injury and protective strategies. Oxid Med Cell Longev 2016: 8254942, 2016.

NGUYEN QL, COREY C, WHITE P, WATSON A, GLADWIN MT, SIMON MA, SHIVA S: Platelets from pulmonary hypertension patients show increased mitochondrial reserve capacity. JCI Insight 2: e91415, 2017.

NICOLSON GL: Mitochondrial dysfunction and chronic disease: treatment with natural supplements. Integr Med 13: 35-43, 2014.

ONG SB, SAMANGOUEI P, KALKHORAN SB, HAUSENLOY DJ: The mitochondrial permeability transition pore and its role in myocardial ischemia reperfusion injury. $J$ Mol Cell Cardiol 78: 23-34, 2015.

ORGANIZATION WH: Noncommunicable diseases progress monitor. 1-231, 2017.

OUYANG J, WU M, HUANG C, CAO L, LI G: Overexpression of oxidored-nitro domain containing protein 1 inhibits human nasopharyngeal carcinoma and cervical cancer cell proliferation and induces apoptosis: Involvement of mitochondrial apoptotic pathways. Oncol Rep 29: 79-86, 2013.

PARKER WD JR, BOYSON SJ, LUDER AS, PARKS JK: Evidence for a defect in NADH: ubiquinone oxidoreductase (complex I) in Huntington's disease. Neurology 40: 1231-1234, 1990a.

PARKER WD JR, BOYSON SJ, PARKS JK: Abnormalities of the electron transport chain in idiopathic Parkinson's disease. Ann Neurol 26: 719-723, 1989.

PARKER WD JR, FILLEY CM, PARKS JK: Cytochrome oxidase deficiency in Alzheimer's disease. Neurology 40: 1302-1303, 1990b.

PERALES VILLARROEL JP, FIGUEREDO R, GUAN Y, TOMAIUOLO M, KARAMERCAN MA, WELSH J, SELAK MA, BECKER LB, SIMS C: Increased platelet storage time is associated with mitochondrial dysfunction and impaired platelet function. $J$ Surg Res 184: 422-429, 2013.

PESTA D, GNAIGER E: High-resolution respirometry: OXPHOS protocols for human cells and permeabilized fibers from small biopsies of human muscle. Methods Mol Biol 810: 25-58, 2012.

PIEL S, EHINGER JK, ELMER E, HANSSON MJ: Metformin induces lactate production in peripheral blood mononuclear cells and platelets through specific mitochondrial complex I inhibition. Acta Physiol (Oxf) 213: 171-180, 2015.

PIETRAFORTE D, VONA R, MARCHESI A, DE JACOBIS IT, VILLANI A, DEL PRINCIPE D, STRAFACE E: Redox control of platelet functions in physiology and pathophysiology. Antioxid Redox Signal 21: 177-193, 2014. 
PIGNATELLI P, PULCINELLI FM, LENTI L, GAZZANIGA PP, VIOLI F: Hydrogen peroxide is involved in collagen-induced platelet activation. Blood 91: 484-490, 1998.

POWERS WJ, HAAS RH, LE T, VIDEEN TO, HERSHEY T, MCGEE-MINNICH L, PERLMUTTER JS: Normal platelet mitochondrial complex I activity in Huntington's disease. Neurobiol Dis 27: 99-101, 2007.

PROTTI A, FORTUNATO F, ARTONI A, LECCHI A, MOTTA G, MISTRALETTI G, NOVEMBRINO C, COMI GP, GATTINONI L: Platelet mitochondrial dysfunction in critically ill patients: comparison between sepsis and cardiogenic shock. Critical Care 19: 2015.

PUSKARICH MA, KLINE JA, WATTS JA, SHIREY K, HOSLER J, JONES AE: Early alterations in platelet mitochondrial function are associated with survival and organ failure in patients with septic shock. $J$ Crit Care 31: 63-67, 2016.

RAO VK, CARLSON EA, YAN SS: Mitochondrial permeability transition pore is a potential drug target for neurodegeneration. Biochim Biophys Acta 1842: 1267-1272, 2014.

RAVI S, CHACKO B, SAWADA H, KRAMER PA, JOHNSON MS, BENAVIDES GA, O'DONNELL V, MARQUES MB, DARLEY-USMAR VM: Metabolic plasticity in resting and thrombin activated platelets. PLoS One 10: e0123597, 2015.

RAZA H, PRABU SK, JOHN A, AVADHANI NG: Impaired mitochondrial respiratory functions and oxidative stress in streptozotocin-induced diabetic rats. Int J Mol Sci 12: 3133-3147, 2011.

REDDY PH: Mitochondrial medicine for aging and neurodegenerative diseases. Neuromolecular Med 10: 291-315, 2008.

REMENYI G, SZASZ R, FRIESE P, DALE GL: Role of mitochondrial permeability transition pore in coated-platelet formation. Arterioscler Thromb Vasc Biol 25: 467-471, 2005.

RENDU F, BROHARD-BOHN B: The platelet release reaction: granules' constituents, secretion and functions. Platelets 12: 261-273, 2001.

RODRIGUEZ-CARRIZALEZ AD, CASTELLANOS-GONZALEZ JA, MARTINEZ-ROMERO EC, MILLERARREVILLAGA G, VILLA-HERNANDEZ D, HERNANDEZ-GODINEZ PP, ORTIZ GG, PACHECOMOISES FP, CARDONA-MUNOZ EG, MIRANDA-DIAZ AG: Oxidants, antioxidants and mitochondrial function in non-proliferative diabetic retinopathy. J Diabetes 6: 167-175, 2014.

RONDINA MT, WEYRICH AS, ZIMMERMAN GA: Platelets as cellular effectors of inflammation in vascular diseases. Circ Res 112: 1506-1519, 2013.

ROTH GA, JOHNSON C, ABAJOBIR A, ABD-ALLAH F, ABERA SF, ABYU G, AHMED M, AKSUT B, ALAM T, ALAM K, ALLA F, ALVIS-GUZMAN N, AMROCK S, ANSARI H, ARNLOV J, ASAYESH H, ATEY TM, AVILA-BURGOS L, AWASTHI A, ET AL.: Global, Regional, and National Burden of Cardiovascular Diseases for 10 Causes, 1990 to 2015. J Am Coll Cardiol 70: 1-25, 2017.

RUSAK T, TOMASIAK M, CIBOROWSKI M: Peroxynitrite can affect platelet responses by inhibiting energy production. Acta Biochim Pol 53: 769-776, 2006.

SCHAEFFER G, WASCHER TC, KOSTNER GM, GRAIER WF: Alterations in platelet Ca2+ signalling in diabetic patients is due to increased formation of superoxide anions and reduced nitric oxide production. Diabetologia 42: 167-176, 1999.

SCHAPIRA AH: Mitochondrial complex I deficiency in Parkinson's disease. Adv Neurol 60: 288-291, 1993.

SCHIFFMANN E, CORCORAN BA, WAHL SM: N-formylmethionyl peptides as chemoattractants for leucocytes. Proc Natl Acad Sci U S A 72: 1059-1062, 1975.

SCHIMMER AD, SKRTIC M: Therapeutic potential of mitochondrial translation inhibition for treatment of acute myeloid leukemia. Expert Rev Hematol 5: 117-119, 2012.

SEMPLE JW, ITALIANO JE JR, FREEDMAN J: Platelets and the immune continuum. Nat Rev Immunol 11: 264-274, 2011.

SIEWIERA K, KASSASSIR H, TALAR M, WIETESKA L, WATALA C: Higher mitochondrial potential and elevated mitochondrial respiration are associated with excessive activation of blood platelets in diabetic rats. Life Sci 148: 293-304, 2016. 
SJOVALL F, EHINGER JK, MARELSSON SE, MOROTA S, FROSTNER EA, UCHINO H, LUNDGREN J, ARNBJORNSSON E, HANSSON MJ, FELLMAN V, ELMER E: Mitochondrial respiration in human viable platelets--methodology and influence of gender, age and storage. Mitochondrion 13: 7-14, 2013.

SJOVALL F, MOROTA S, HANSSON MJ, FRIBERG H, GNAIGER E, ELMER E: Temporal increase of platelet mitochondrial respiration is negatively associated with clinical outcome in patients with sepsis. Crit Care 14: R214, 2010.

SMYTH SS, MCEVER RP, WEYRICH AS, MORRELL CN, HOFFMAN MR, AREPALLY GM, FRENCH PA, DAUERMAN HL, BECKER RC: Platelet functions beyond hemostasis. J Thromb Haemost 7: 1759-1766, 2009.

STERNFELD T, TISCHLEDER A, SCHUSTER M, BOGNER JR: Mitochondrial membrane potential and apoptosis of blood mononuclear cells in untreated HIV-1 infected patients. HIV Med 10: 512-519, 2009.

STURZA A, PAVEL I, ANCUSA S, DANCIU C, DEHELEAN C, DUICU O, MUNTEAN D: Quercetin exerts an inhibitory effect on cellular bioenergetics of the B164A5 murine melanoma cell line. Mol Cell Biochem 447: 103-109, 2018.

SUMBALOVÁ Z, CIZMAROVA B, VOLANI C, GNAIGER E: Analysis of mitochondrial function in human blood cells. In: Recent Advances in Mitochondrial Medicine and Coenzyme Q10. GVOZDJÁKOVÁ A, CORNÉLISSEN G, SINGH RB (eds), Nova Sciences, 2018, pp 255-268.

THUSHARA RM, HEMSHEKHAR M, BASAPPA, KEMPARAJU K, RANGAPPA KS, GIRISH KS: Biologicals, platelet apoptosis and human diseases: An outlook. Crit Rev Oncol Hematol 93: 149-158, 2015.

TOMASIAK M, STELMACH H, RUSAK T, WYSOCKA J: Nitric oxide and platelet energy metabolism. Acta Biochim Pol 51: 789-803, 2004.

TOMKIN GH, OWENS D: Dyslipidaemia of diabetes and the intestine. World J Diabetes 6: 970-977, 2015.

TSCHOEPE D, ROESEN P, ESSER J, SCHWIPPERT B, NIEUWENHUIS HK, KEHREL B, GRIES FA: Large platelets circulate in an activated state in diabetes mellitus. Semin Thromb Hemost 17: 433-438, 1991.

TYRRELL DJ, BHARADWAJ MS, JORGENSEN MJ, REGISTER TC, MOLINA AJ: Blood cell respirometry is associated with skeletal and cardiac muscle bioenergetics: Implications for a minimally invasive biomarker of mitochondrial health. Redox Biol 10: 65-77, 2016.

VALLA J, SCHNEIDER L, NIEDZIELKO T, COON KD, CASELLI R, SABBAGH MN, AHERN GL, BAXTER L, ALEXANDER G, WALKER DG, REIMAN EM: Impaired platelet mitochondrial activity in Alzheimer's disease and mild cognitive impairment. Mitochondrion 6: 323-330, 2006.

VEVERA J, FISAR Z, NEKOVAROVA T, VRABLIK M, ZLATOHLAVEK L, HROUDOVA J, SINGH N, RABOCH J, VALES K: Statin-induced changes in mitochondrial respiration in blood platelets in rats and human with dyslipidemia. Physiol Res 65: 777-788, 2016.

VIEIRA-DE-ABREU A, CAMPBELL RA, WEYRICH AS, ZIMMERMAN GA: Platelets: versatile effector cells in hemostasis, inflammation, and the immune continuum. Semin Immunopathol 34: 5-30, 2012.

WALLACE DC: A mitochondrial bioenergetic etiology of disease. J Clin Invest 123: 1405-1412, 2013.

WANG L, WU Q, FAN Z, XIE R, WANG Z, LU Y: Platelet mitochondrial dysfunction and the correlation with human diseases. Biochem Soc Trans 45: 1213-1223, 2017.

WANG R, STONE RL, KAELBER JT, ROCHAT RH, NICK AM, VIJAYAN KV, AFSHAR-KHARGHAN V, SCHMID MF, DONG JF, SOOD AK, CHIU W: Electron cryotomography reveals ultrastructure alterations in platelets from patients with ovarian cancer. Proc Natl Acad Sci U S A 112: 14266-14271, $2015 \mathrm{a}$.

WANG Z, WANG J, XIE R, LIU R, LU Y: Mitochondria-derived reactive oxygen species play an important role in Doxorubicin-induced platelet apoptosis. Int J Mol Sci 16: 11087-11100, 2015b.

XU W, CARDENES N, COREY C, ERZURUM SC, SHIVA S: Platelets from asthmatic individuals show less reliance on glycolysis. PLoS One 10: e0132007, 2015.

WIDLANSKY ME, WANG J, SHENOUDA SM, HAGEN TM, SMITH AR, KIZHAKEKUTTU TJ, KLUGE MA, WEIHRAUCH D, GUTTERMAN DD, VITA JA: Altered mitochondrial membrane potential, mass, and morphology in the mononuclear cells of humans with type 2 diabetes. Transl Res 156: 15-25, 2010.

WORLDHEALTHORGANIZATION: Global Health Estimates 2016: Deaths by Cause, Age, Sex, by Country and by Region, 2000-2016. Geneva 2018. 
WU F, LIU Y, LUO L, LU Y, YEW DT, XU J, GUO K: Platelet mitochondrial dysfunction of DM rats and DM patients. Int J Clin Exp Med 8: 6937-6946, 2015.

YAMAGISHI SI, EDELSTEIN D, DU XL, BROWNLEE M: Hyperglycemia potentiates collagen-induced platelet activation through mitochondrial superoxide overproduction. Diabetes 50: 1491-1494, 2001.

ZHARIKOV S, SHIVA S: Platelet mitochondrial function: from regulation of thrombosis to biomarker of disease. Biochem Soc Trans 41: 118-123, 2013. 